\title{
Desain Skuter Selam Pribadi Untuk Kegiatan Rekreasi Dengan Konsep Dua Posisi Berkendara
}

\author{
Adiguna Kharismawan dan Andhika Estiyono \\ Departemen Desain Produk Industri, Fakultas Teknik Sipil dan Perencanaan, \\ Institut Teknologi Sepuluh Nopember (ITS) \\ e-mail: andhika@prodes.its.ac.id
}

\begin{abstract}
Abstrak-Rekreasi bawah laut digemari oleh wisatawan di seluruh dunia. daya tarik dari pesona wisata bawah laut adalah keanekaragaman biota terutama terumbu karang. Fakta bahwa snorkeling dan scuba diving merupakan kegiatan yang juga ikut andil dalam perusakan habitat laut menjadi peluang untuk memperkembangkan rancangan DPV sebagai kendaraan bagi diver dan snorkeler untuk ikut dalam kampanye perlindungan terumbu karang di seluruh dunia karena DPV bisa menggantikan fin yang sering mengenai terumbu karang saat dikibaskan. Konsep skuter selam pribadi dengan dua posisi berkendara menjadi konsep dalam perancangan ini yang bertujuan untuk menghasilkan DPV (Diver Propulsion Vehicle) yang ergonomis saat berada di air dan di darat. Konfigurasi komponen utama di dalam DPV dan tambahan fitur action cam serta GPS. DPV ini ditujukan untuk dua pengoperasian yang bisa digunakkan untuk scuba diver dan snorkeler, untuk itu penelitian ini menggunakkan metode analisa terhadap user dan DPV eksisting.
\end{abstract}

Kata kunci: DPV, selam, terumbu karang, action cam, scuba diving, snorkeling

\begin{abstract}
Underwater recreation is favored by tourists all over the world. The attractiveness of the underwater tourism charms is it marine life, especially coral reefs. The fact that snorkeling and scuba diving is an activity that also contributes to the destruction of marine habitats is an opportunity to develop the DPV design as a vehicle for diver and snorkeler to participate in coral reef protection campaigns around the world as DPV can replace the frequent fin on coral reefs when wagged. The concept of a private dive scooter with two driving positions becomes a concept in this design that aims to produce an ergonomic DPV (Diver Propulsion Vehicle) while on the water and on land. Configure the main components inside DPV and additional cam and cam action features. DPV is intended for two operations that can digunakkan for scuba diver and snorkeler, for that this research method of analysis of the user and existed DPV.
\end{abstract}

Key words: DPV, diving, coral rock, action cam, scuba diving, snorkeling

\section{PENDAHULUAN}

Terumbu karang di Indonesia sangat terkenal akan kecantikan dan jenisnya yang beragam. Kecantikan biota laut ini menawarkan peluang usaha persewaan alat selam baik selam permukaan maupun selam SCUBA di berbagai spot yang ternama seperti di pulau Lombok dan Flores. Taman laut yang tersebar di seluruh Indonesia seperti di taman nasional Bunaken memiliki luas +/- 890km persegi dan 390 spesies, karena itu taman laut menjadi surge bagi para penggiat rekreasi bawah laut. Snorkeling dan scuba diving yang selalu menjadi andalan wisata bahari menjadi salah satu aktifitas yang ikut andil dalam merusak terumbu karang yang ada di sekitar taman laut karena factor rendahnya kesadaran penyelam untuk menjadi responsible diver yang selalu bertanggung jawab terhadap perlindungan lingkungan sekitar. Sebenarnya, di dalam agensi yang mengeluarkan sertifikat untuk scuba diving seperti PADI dan SSI mempunyai program yang selalu mengingatkan tentang perlindungan lingkungan laut.

Aktifitas pendukung dalam kegiatan rekreasi bawah laut adalah memotret dan atau merekam menggunakan action cam yang kini kian marak digunakan oleh wisatawan. Action Cam sendiri awalnya digunakan para atlet olahraga ekstrem untuk mendokumentasikan kegiatan mereka saat berolahraga tanpa harus bersusah payah mengoperasikannya. GoPro adalah pionir dalam action cam, namun perlahan mulai bermunculan produk action cam yang jauh lebih murah seperti SJcam, Xiaomi, dan B-Pro. Penjualan action cam dengan harga yang terjangkau di masyarakat, membuat peminatnya setiap tahun meningkat drastic, terutama para wisatawan yang menggunakannya untuk snorkeling dan scuba diving karena setiap action cam juga dilengkapi dengan waterproof case [1, 2 dan 3].

Saat ini Indonesia mulai mengadakan beberapa wahana untuk mempermudah wisatawan menikmati keindahan bawah laut. Salah satu wahananya adalah DPV (Diver Propulsion Vehicle). DPV merupakan wahana personal untuk memperluas jangkauan area menyelam. Wahana atau alat ini biasa digunakan untuk penelitian, militer maupun rekreasi. DPV mempermudah penyelam untuk bergerak ke mana pun dan bisa mengurangi penggunaan kaki katak (fin) saat berdekatan dengan terumbu karang karena para penyelam umumnya mengibaskan kakinya dengan tak terkendali sehingga menyebabkan rusaknya terumbu karang [4, 5 dan 6].

Desain $D P V$ yang sudah ada di pasaran adalah jenis diver tug atau penyelam ditarik menggunakan DPV (Gambar 1). Berdasarkan hasil pengamatan dengan metode shadowing terhadap penggunaan Wesley $D P V$, pengoperasian $D P V$ jenis diver tug ini dimulai dengan pre-operational check hingga pemeriksaan setelah dipakai. Namun terdapat beberapa masalah yang dijumpai ketika menggunakan alat ini. Masalah pertama ialah penyelam mengalami kesulitan saat terjadi masalah dengan scuba gear-nya sedangkan kedua tangan penyelam harus memegang $D P V$. Masalah kedua dan terakhir adalah pengguna sering lupa untuk menutup katup vakum karena bentuk katup tidak terlalu mencolok serta tidak ada senter dan posisi ballast room yang membuat adanya dorongan ke atas di bagian depan [7, 8, 9 dan 10]. 


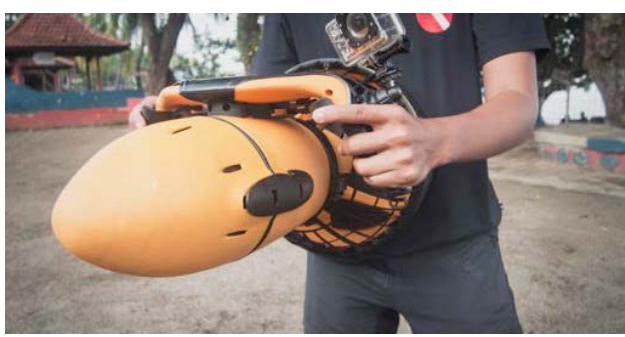

Gambar 1. DPV Eksisting

\section{METODE PENELITIAN}

\section{Tahap Pengambilan Data}

Proses penelitian dilakukan dengan menggunakkan metode seperti depth interview, observasi, shadowing dan membongkar alat DPV eksisting serta beberapa data literatur bersumber dari buku dan internet yang menunjang perancangan. Penelitian akan dimulai dengan analisa dari DPV untuk menentukan positioning dan performa yang disesuaikan dengan pengguna, analisa user terhadap gaya hidupnya dan ukuran tubuh. Analisa laut untuk mendapatkan batasan apa saja dalam merancang skuter selam agar tidak merugikan lingkungan dan penyelam.

\section{Tahap Studi Analisa}

Tahapan studi dan analisa meliputi bagaimana mendesain sebuah skuter selam (DPV) agar bisa digunakan dengan nyaman oleh pengguna dan tidak merusak lingkungan [11, 12, 13 dan 14]. Berikut adalah tahapan studi dan analisa yang telah dilakukan:

1. Analisa positioning dan demografi.

Analisa ini ditujukan sebagai penentu batasan target pengguna dan tren wisata bawah laut saat ini.

2. Analisa aktifitas.

Analisa ini bertujuan untuk memahami kebutuhan user dan menggali permasalahan yang muncul saat mengoperasikan DPV.

3. Analisa konfigurasi DPV.

Fungsi dari analisa ini adalah untuk mengetahui konfigurasi yang ideal dengan komponen utama yaitu baterai, motor, dan ballast room.

4. Analisa water entry.

Analisa ini dibutuhkan untuk menentukan posisi DPV yang ideal agar mudah saat penyelam melakukan proses water entry.

5. Analisa mounting action cam.

Dengan melihat action cam yang sedang tren di pasaran lalu diambil mounting apa yang cocok untuk diletakkan pada DPV, kemudian dilakukan analisa terhadap tata letak dari mounting action cam.

6. Analisa material.

Ada beberapa material yang menjadi pilihan untuk dipakai di DPV yaitu aluminium, fiber dan HDPE. Analisa ini berguna untuk melihat keunggulan dari beberapa material tersebut dan menentukan material yang sesuai untuk sebuah DPV.

7. Analisa ergonomi.

Analisa ini dibutuhkan untuk menentukan beberapa bagian yang menyangkut kenyamanan dalam mengoperasikan DPV, seperti pada control handle dan carry handle.

8. Analisa scuba tank.

Bertujuan untuk menentukan jenis scuba tank yang akan dipakai sebagai acuan bentuk DPV. selain itu, analisa ini digunakan untuk mendapatkan tahapan pemasangan DPV dan sistem pemasangan pada scuba tank.

9. Analisa prosedur keselamatan.

Prosedur keselamatan merupakan bagian terpenting pada dunia rekreasi bawah laut. Dengan adanya analisa prosedur keselamatan, dapat diketahui solusi untuk mengatasi permasalahan pada kegiatan penyelaman ketika sedang mengoperasikan DPV.

10. Analisa senter selam.

Senter selam merupakan fitur DPV yang menyangkut faktor safety dan videografi, karena apabila tidak ada senter saat menyelam ke lautan yang lebih dalam, maka warna dan cahaya matahari pun berkurang sehingga penyelam kesulitan untuk melihat sekitar. Analisa konfigurasi senter juga dilakukan untuk melihat posisi yang sesuai pada DPV.

11. Analisa jenis motor dan baterai.

Motor dan baterai adalah komponen penggerak listrik utama. Analisa ini berfungsi untuk menentukan komponen yang bisa menggerakkan bobot manusia di dalam air dengan halangan arus laut.

12. Analisa pengembangan bentuk.

Proses pengembangan bentuk adalah tahapan desain terakhir sebelum masuk ke tahap produksi. Proses pengembangan bentuk ini ditentukan dari kesimpulan beberapa analisa seperti analisa ergonomi, aerodinamis, dan komponen pengisi serta estetika.

Batasan permasalahan pada desain mencakup :

1. Pemilihan dan penggunaan material yang kuat untuk melewati tekanan saat dibawa ke kedalaman laut maksimal hingga 40 meter.

2. Memudahkan kedua tangan penyelam untuk tetap beroperasi melakukan aktifitas yang lain.

3. Memiliki mounting untuk action cam.

4. Posisi ballast room yang tepat tidak menimbulkan hambatan saat dioperasikan

5. Air tight lock pada ruang vakum diperjelas agar tidak terjadi kelupaan menutup

6. Target user adalah usia 25-40 tahun, pria dan wanita berdomisili di kota besar yang dekat dengan spot penyelaman dan berpenghasilan menengah ke atas

7. Dapat digunakan dengan dua cara penyelaman, yaitu dengan cara snorkeling dan scuba diving. DPV ini diletakkan pada tabung scuba dan bisa digunakan seperti DPV biasa.

\section{HASIL DAN PEMBAHASAN}

\section{Konsep Perancangan}

Dari hasil analisa yang telah dilakukan, didapatkan kesimpulan konsep yang akan dipakai pada perancangan desain DPV. Konsep ini didapat berdasarkan berbagai permasalahan dari hasil semua analisa.

Kegiatan rekreasi adalah kegiatan yang dilakukan oleh orang di waktu senggang untuk kesenangan dan rileksasi. Kegiatan rekreasi bisa dilakukan dimana saja termasuk di bawah laut. Wisatawan bahari dihiburkan oleh keindahan susunan biota laut dan biasanya mereka melakukan aktifitas snorkeling dan scuba diving untuk menikmati keindahan biota laut tersebut.

Konsep desain pada rancangan DPV ini mengacu pada kedua kegiatan snorkeling dan scuba diving dengan sebuah rancangan DPV yang bisa dipakai oleh dua jenis kegiatan tersebut [15, 16, 17 dan 18].

\section{Fitur}

Berikut adalah beberapa fitur yang di aplikasikan pada rancangan DPV ini [19, 20 dan 21]:

\section{Handsfree operated}

Fitur handsfree operated adalah fitur yang diilhami dari masalah saat melakukan penyelaman menggunakan DPV, penyelam tidak bisa menggunakan kedua tangannya untuk aktifitas yang lain (Gambar 2). DPV diletakkan di tabung 
scuba lalu control handle dapat dilepas dan dikontrol jarak jauh menggunakan kabel.

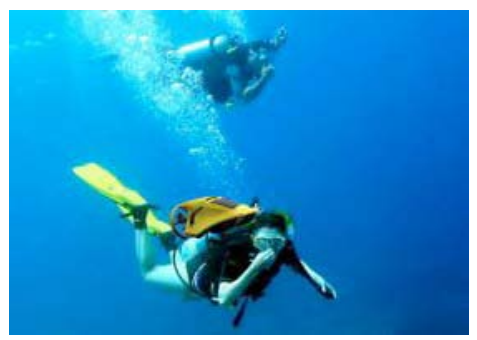

Gambar 2. Handsfree Operated

2. Dual mode position

Gambar 3 menunjukkan fitur dual mode merupakan fitur utama rancangan DPV ini, yaitu dapat dipakai untuk scuba diving dengan meletakkan pada tabung scuba dan bisa juga digunakan untuk snorkeling dengan dipegang seperti DPV biasa.

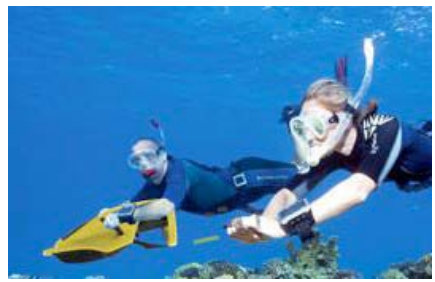

Gambar 3. Dual mode position

3. Action cam mount

Permintaan wisatawan terhadap action cam semakin meningkat setiap tahunnya. Para wisatawan umumnya merekam kegiatan mereka selama di bawah laut menggunakan action cam dengan waterproof case hingga kedalaman 30 meter (Gambar 4). Fenomena ini dapat disimpulkan bahwa penting untuk menambahkan fitur berupa mounting action cam.

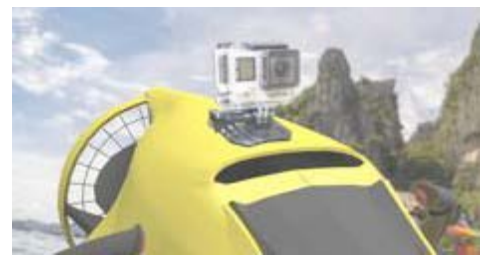

Gambar 4. Action cam mount

4. Easy to carry

Dari permasalahan yang didapat menggunakan metode shadowing, yaitu terjadi kesulitan saat membawa DPV dari pinggir pantai sampai laut/boat dan saat buddy memberi DPV kepada diver yang ada di laut maka perlu ada tambahan handle yang khusus untuk memudahkan saat dibawa (Gambar 5). Handle berada diatas jadi posisi DPV saat dibawa tegak berdiri agar air mudah keluar dari celah.

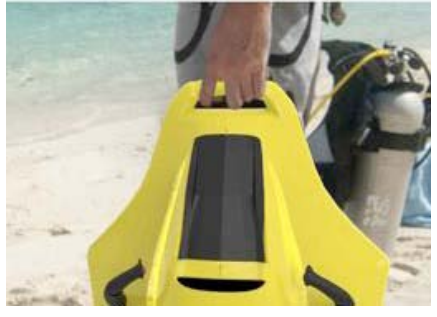

Gambar 5. Easy to carry

5. GPS (Global Positioning System)

Kegiatan penyelaman termasuk kegiatan ekstrim dan pastinya tidak luput dari bencana yang akan mengenai penyelam (Gambar 6). Salah satunya saat penyelam dinyatakan hilang karena pingsan atau terpisah dari rombongan. Penyelam yang sadar akan melakukan emergency ascent (menuju permukaan) dan jika hilang GPS pada DPV akan memancarkan sinyal saat DPV berada di permukaan maka penyelam dapat diketahui posisinya.

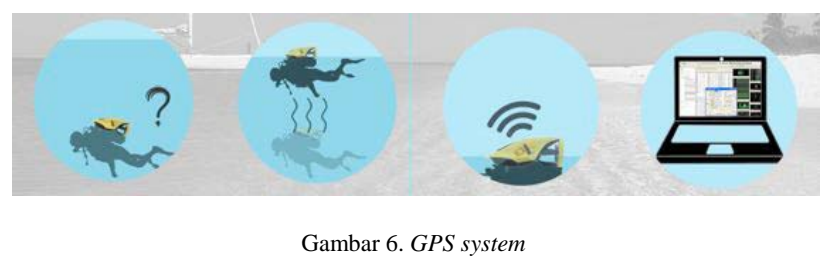

Studi model dilakukan untuk mengetahui posisi ergonomi sebuah DPV dari hasil analisa ergonomi dan juga melihat ukurannya (Gambar-gambar 7 dan 8). Studi model diproduksi menggunakan material PU (Polyurethane) foam. Lalu, dari model yang telah dibuat dan ditelaah akan diproses desain sketsa lalu digambar secara 3D menggunakan software 3ds Max.

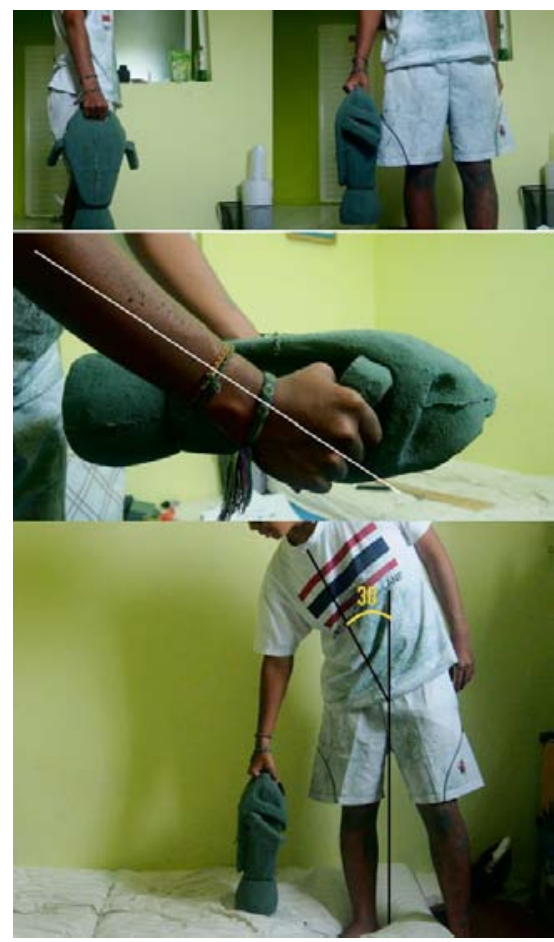

Gambar 7. Studi model handel produk 


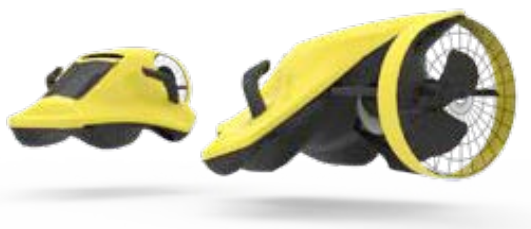

Gambar 8. 3D Model

Proses pengembangan untuk bentuk dari DPV merupakan tahapan desain terakhir sebelum dilanjutkan ke tahap produksi. Proses pengembangan bentuk ini ditentukan dari gabungan beberapa kesimpulan analisa seperti analisa ergonomi, analisa aerodinamis , komponen pengisinya serta aspek estetika.

6. Komponen pengisi

Komponen pengisi adalah bagian dalam sebuah DPV yang diantaranya adalah senter, motor, baterai. Komponen ini sangat mempengaruhi bentuk sebuah DPV. Karena komponen pengisi ini adalah otak agar DPV bisa dioperasikan.

7. Aspek ergonomi

Ergonomi pada DPV lebih difokuskan pada carry handle dan control handle, posisi control handle akan menentukan posisi pengguna mencapai posisi yang tepat saat menggunakan unit DPV. Kedua handle ini mempunyai ketebalan yang sama karena kedua handle tersebut sama sama menggunakkan kekuatan yang cukup besar dari tangan.

8. Metaformosis

Selain dari hasil analisa secara teknis, bentuk DPV mengambil dari metamorphosis ikan pari manta yang merupakan hewan langka yang berada di laut Indonesia (Gambar 9). Ikan pari manta merupakan ikan jenis pari berukuran sangat besar yang tinggal di lautan tropis. Meskipun ikan pari ini terkesan menakutkan dan sangat besar tapi ikan pari manta selalu bersahabat dengan para mahluk lainnya termasuk manusia yang berenang di sekitarnya. Ikan pari manta berenang sambil mengibaskan sayapnya dengan sangat tenang namun cepat, hal itu yang menjadi alasan untuk mengadaptasi estetika bentuk rancangan DPV dari ikan pari manta.

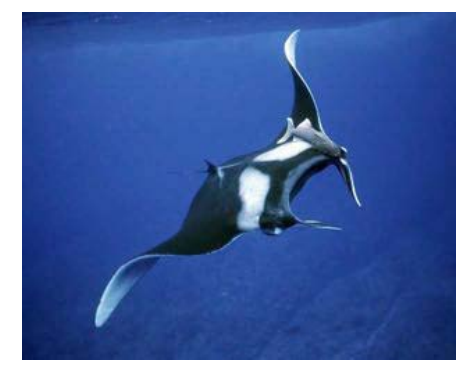

Gambar 9. Pari Manta

\section{Proses Produksi Prototype}

Sebelum melakukan produksi massal menggunakkan material pilihan yaitu HDPE maka dilakukan pembuatan prototype untuk uji coba kasus sesuai kenyataan. Pembuatan prototype menggunakkan material komposit resin fiberglass karena proses pembuatan yang tidak semahal HDPE.

Tahapan proses pembuatan adalah sebagai berikut:

1. Pembuatan master cetakan

Membuat master cetakan adalah langkah awal dari pembuatan produk resin fiberglass. Master ini nantinya bisa dipakai juga untuk produksi missal. Pembuatan master dimulai dengan membuat polyurethane foam. Polyurethane foam dipilih karena memiliki kekuatan disbanding styrofoam dan kepadatannya membuat foam mudah diukir menggunakkan blade. Polyurethane memiliki dua komponen A (bahan dasar) \& B (hardener) dengan perbandingan 1:1 (Gambar-gambar10 dan 11).

Setelah polyurethane membentuk foam yang massif, diukir menggunakkan mesin cnc sesuai dengan 3d design. Foam yang telah diukir/dibentuk selanjutnya dilapisi dengan resin fiberglass berlapis lapis hingga ketebalan $4 \mathrm{~mm}$. setelah itu pemisahan cetakan resin fiberglass dari polyurethane foam.

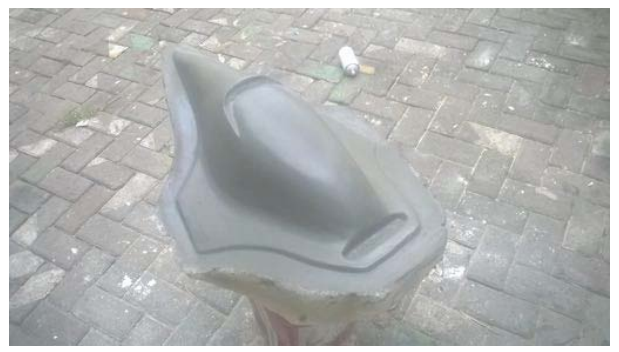

Gambar 10. Master cetakan

2. Pembuatan fiberglass hasil.

Mencetak fiberglass hasil dari master cetakan dengan menuang campuran resin pada master lalu diratakan dan dilapisi dengan fiberglass, proses ini dilakukan berulang kali sampai ketebalan $4 \mathrm{~mm}$ lalu setelah kering fiberglass hasil dilepas dari master cetakan.

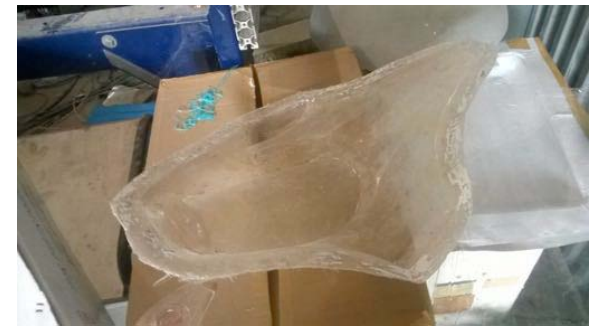

Gambar 11. Hasil model bahan fiberglass

\section{Langkah finishing}

Merapikan fiberglass yang terlepas dari cetakan dengan menggunting/menggergaji dan menggerinda bibir. Apabila hasil fiberglass telah rapi dapat dilakukan proses menggabungkan kedua sisi atas dan bawah apabila memiliki 2 sisi lalu setelah digabungkan dilanjutkan pengamplasan permukaan, pendempulan dan pengecatan lalu kemudian diakhiri dengan pengisian komponen komponen utama seperti Buoyancy chamber, battery, mesin dan komponen listrik lainnya (Gambar 12).

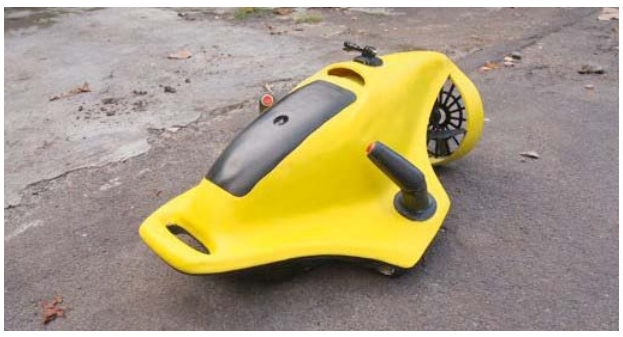

Gambar 12. Hasil jadi

\section{KESIMPULAN}

Berdasarkan penelitian dan perancangan produk DPV ini dapat disimpulkan bahwa:

1. Untuk menghasilkan suatu rancangan DPV yang bisa operasikan secara normal dibutuhkan beberapa uji coba 
kelayakan yang diantara lain seperti uji coba kekedapan air, ketahanan material terhadap tekanan dan konfigurasi komponen dalam yang mempengaruhi stabilitas DPV

2. Dengan adanya rancangan DPV ini dapat membantu penyelam untuk mengetahui tentang mengurangi penggunaan fin yang sering melukai terumbu karang

3. Rancangan ini menghasilkan mock-up pertama DPV berbahan dasar resin fiber dengan ergonomi yang sesuai namun jenis komponen serta konfigurasinya masih belum memenuhi standar.

Untuk pengembangan produk lebih lanjut, maka penulis memberikan saran yang sangat bermanfaat, seperti:

1. Untuk uji coba ergonomi dan sistem kerja pada fitur dapat dilakukan dengan menggunakkan bahan yang mudah untuk dibuat dengan cepat seperti pipa paralon/PVC karena uji coba akan dilakukan berulang kali dengan unit yang berbeda

2. Perlu diperhatikan untuk kemudahan unit ketika akan dipasang ke tabung scuba agar tidak merusak unit

3. Untuk penggunaan fitur GPS, pengguna harus bisa membaca titik koordinat dengan mudah dan cepat.

4. Ada kelemahan pada control handle dimana pengguna lebih memilih memegang bagian bawah handle karena pengguna merasa takut jika memegang bagian atas yang terlihat mudah untuk lepas, karena itu dibutuhkan control handle yang secara visual sangat kokoh dan menyatu antara bagian atas dan bawah

\section{DAFTAR PUSTAKA}

[1] Dell, D. 2009. Manta DPV. Retrieved september 2015, from http://www.coroflot.com/ddell/graduate-project-diverpropulsion- vehicle-

[2] DEMIRAG, M. (2014). Retrieved November 2015, from www.divewithseaman.com/new-hollis-h-160-underwaterscooter-DPV- review/

[3] Fiskal. (2014). Mengenal anatomi rentang penghasilan. Retrieved november 2015,

[4] Gooddive. (2008). Scuba diving procedure. Retrieved december 13, 2015, from http://www.gooddive.com/forum-scuba-diving/diversforum/96-open-water-dive-procedure.html

[5] Gopro. (2015). Gopro HERO Black 4. Retrieved december 2015,

from http://shop.gopro.com/Marketing/cameras/hero4black/CHDHX-401-EU.html

[6] Gopro. (2015). Replacement part. Retrieved november 2015, from http://shop.gopro.com/Marketing/mounts/replacementparts/AGBAG- 001.html

[7] Inc, P. M. (2002). Pegasus Thruster. Retrieved november 4, 2015, from http://pegasusthruster.com/buy_pegasus_thruster_dpv.php

[8] Inc, T. (2009). Torpedo DPV. Retrieved december 2015, from http://www.torpedodpv.com/models.php

[9] ISO.(2015). ISO. Retrievedoctober 2015, from http://www.iso.org/iso/home/about.htm

[10] Hanington, B. (2012). Universal Methods of Design: 100 Ways to Research Complex Problems, Develop Innovative Ideas, and Design Effective Solutions (Vol. I). Beverly: Rockpot Publishers.

[11] Hines, S. (2013). Drag Reduction for Submarine. Retrieved november 2015, from http://www.hineslab.com/dragreduction-for-submarines/

[12] Kinetics, UCB schools of Human. (1998). Fluid and Flight Mechanics. Retrieved november10, 2015, from http://faculty.educ.ubc.ca/sanderson/courses/HKIN151/note s/fluidn4.ht m
[13] Lifehacker. (2015). Most Popular Action Camera : Gopro HERO Black 4. Retrieved december 2015, from http://lifehacker.com/five-best-action- cameras$1711022789 / 1711802009$

[14] Mares. (2015). Products. Retrieved december 2015, from https://www.mares.com/?region=eu

[15] Mcgraw, C. (Director). (2014). GoPro Hero 4 Black Edition [Motion Picture].

[16] Molland, A. E. (2008). The Maritime Engineering Book A Guide To Ship Design , Construction and Operation. Southampton: $\mathrm{BH}$.

[17] OPCON. (2014). Black Ace Military. Retrieved december 2015, from http://www.opcon.com.sg/cms/index.php/products/blackace

[18] Pro, L. (2009). Scuba Diving Water Entry Method. Retrieved december 2015, from https://www.leisurepro.com/blog/scuba-guides/scubadiving- water-entry-methods/

[19] Subwing. (2014). Subwing Carbon Glossy. Retrieved november 23, 2015, from

http://www.subwing.com/products/subwings/subwingcarbon-glossy.html\#.Vm_oGRp96Rs

[20] Seadoo. (2009). Seadoo Seacscooter. Retrieved october 15, 2015,

from http://www.seadooseascooter.com/products.html

[21]Tusa. (2015). Tusa SAV -7 . Retrieved october 2015, from www.tusa.com/mx-en/Tusa/DPV:scooter/SAV7_Evolution 